\title{
O PAPEL DO ASSISTENTE SOCIAL NO ACOLHIMENTO E NA GARANTIA AO ACESSO DOS USUÁRIOS AOS PROGRAMAS DA REDE SUS
}

\author{
THE ROLE OF THE SOCIAL WORKER IN WELCOMING AND \\ GUARANTEEING USER ACCESS TO SUS NETWORK PROGRAMS
}

Ana Carla Madeira de Carvalho dos Anjos Oliveira ${ }^{\mathrm{I}}$

Paulo Menis ${ }^{2}$

RESUMO: No contexto de informação em saúde, destaca-se a promoção da saúde como o processo no qual os indivíduos são capacitados para ter maior controle sobre a própria saúde, reconhecendo a importância do poder e do controle sobre os determinantes da saúde, utilizando-se de estratégias que visem a empoderar os sujeitos, aumentando sua participação na modificação dos elementos relevantes à saúde. A informação tornou-se uma necessidade crescente para qualquer setor da atividade humana e é indispensável mesmo que a sua procura não seja ordenada ou sistemática, mas resultante apenas de decisões casuísticas e/ou intuitivas. Este artigo visa a realizar uma reflexão crítica sobre a importância da informação sobre os direitos do usuário na saúde pública para a promoção e estímulo ao empoderamento e libertação da população, vislumbrando sua participação mais ativa sobre os assuntos relacionados à sua saúde.

Palavras-chave: Informação; Acolhimento; Promoção da Saúde; Participação.

ABSTRACT: In the context of health information, there is the health promotion as the process in which individuals are able to have greater control over their own health, recognizing the importance of power and control over the determinants of health, using the strategies to empower individuals by increasing their participation in the modification of elements relevant to health. The information has become an increasing necessity for any sector of human activity and is essential even if their demand is not orderly or systematic, but resulting only of samples and / or intuitive decisions. This article aims to make a critical reflection on the importance of information about user rights in public health to promoting and encouraging the empowerment and liberation of people, seeing their more active participation on matters related to your health.

\footnotetext{
${ }^{1}$ Graduada em Serviço Social pela Universidade Anhanguera UNIDERP (2014) e Graduada em Gestão em Serviço Social e Políticas Públicas pelo Instituto Nordeste de Educação Superior e Pós-Graduação INESPO (2018).E- mail: assistentecarla@gmail.com.

${ }^{2}$ Mestre em Educação pela Universidade Católica de Brasília- UNB
} 
Keywords: Information; Host; Health Promotion; Involvement.

\section{INTRODUÇÃO}

Dentro do presente estudo abordamos o papel do Assistente Social no acolhimento e na garantia ao acesso dos usuários aos programas da rede SUS, enfatizamos a importância da informação para toda e qualquer situação em nossa sociedade e alcançamos resultados afirmativos acerca do problema levantado.

$\mathrm{O}$ acolhimento e a informação têm sido discutidos de maneira emblemática no campo da saúde e tratado no campo das práticas fundamentadas no princípio da integralidade, no campo da ética e no âmbito da própria política de saúde, particularmente, como diretriz da atual Política Nacional de Humanização.

A informação assume, hoje em dia, uma importância crescente. Ela torna-se fundamental a nível de descobertas e introdução de novas tecnologias, exploração das oportunidades e ainda na efetivação de serviços, principalmente na área da saúde, que é um direito universal de todo e qualquer cidadão.

O acolhimento caminha junto com a informação, pois durante o processo de acolhimento o usuário pode e deve receber as informações devidas ao que está buscando.

O (A) Assistente Social está comprometido (a) diretamente com o ato de acolher, de informar e de garantir direitos, para isso, muitos são os desafios enfrentados, afinal, um profissional que atua na área da saúde lida com a defesa da vida no seu cotidiano.

Queremos chamar a atenção para a ideia de que o acolhimento e a informação devem estar presentes em todas as relações e em todos os serviços e com isso contribuir para o aperfeiçoamento da rede SUS.

\section{DIREITOS DOS USUÁRIOS DE SAÚDE PÚBLICA}

Antes do ano de 1988, o atendimento dos hospitais públicos era restrito (BRASIL, 2014), o Sistema público de saúde atendia a quem contribuía para a Previdência Social, era centralizado e de responsabilidade federal, sem participação dos usuários. Quem não tinha condições financeiras dependia da 'caridade e da filantropia'. 
Hoje o sistema público de saúde é para todos (BRASIL, SUS, 2014), sem discriminação, desde a gestação e por toda a vida, a atenção integral à saúde é um direito, conforme a Constituição de 1988. Atualmente é descentralizado, municipalizado e participativo, tendo como princípios norteadores: promoção, proteção, recuperação e reabilitação.

O Ministério da Saúde (Brasil, I990c) adota o termo 'resolutividade', e supõe sua ocorrência mediante a exigência do indivíduo que busca um serviço de saúde para o seu atendimento, ou pelo surgimento de um problema coletivo impactante sobre a saúde da população, e considera que para ser atingido seriam necessários serviços capacitados para resolver esses problemas.

É importante lembrar também dos princípios do SUS que defendem a equidade, a universalização do acesso a bens e serviços relativos às políticas $e$ programas sociais no campo da saúde.

Articulando estes princípios mencionados e as três dimensões que devem compor a prática profissional, podem ser elaboradas novas possibilidades de acesso e de intervenção por parte do Serviço Social em relação aos usuários do SUS.

No Brasil, o direito de acesso à informação pública foi previsto na Constituição Federal (BRASIL, 1988), no artigo $5^{\circ}$, inciso XXXIII do Capítulo I, dos Direitos e Deveres Individuais e Coletivos - que dispõe:

\footnotetext{
'Todos têm direito a receber' dos órgãos públicos informações de seu interesse particular, ou de interesse coletivo ou geral, que serão prestadas no prazo da lei, sob pena de responsabilidade, ressalvadas aquelas cujo sigilo seja imprescindível à segurança da sociedade e do Estado.
}

Tendo o propósito de regulamentar o direito, foi promulgada a lei $\mathrm{n}^{\circ}{ }_{12.527}$ (BRASIL, 20II), com direito constitucional de acesso dos cidadãos às informações públicas e seus dispositivos são aplicáveis aos três Poderes da União, Estados, Distrito Federal e Municípios.

Segundo Zhang (1988) o conceito de informação deriva do latim e significa 'um processo de comunicação ou algo relacionado com comunicação, mas na realidade existem muitas e variadas definições de informação, cada uma mais complexa que 
outra'. Podemos também dizer que informação é um processo que visa o conhecimento, ou, mais simplesmente, informação é tudo o que reduz a incerteza. ' $U m$ instrumento de compreensão do mundo e da ação sobre ele' (Zorrinho, 1995, p 15).

A informação tornou-se uma necessidade crescente para qualquer setor da atividade humana e é indispensável mesmo que a sua procura não seja ordenada ou sistemática, mas resultante apenas de decisões casuísticas ou intuitivas, isso também vem com a globalização.

Por essa razão, a tarefa de manter os usuários informados quanto aos serviços ofertados na área da saúde é de fundamental importância. Dessa forma, com este estudo, poderemos contribuir com pesquisas científicas, cooperando para o desenvolvimento do tema proposto.

Sendo assim no ambiente hospitalar, a intervenção e interação do Assistente Social é primordial para a transferência de informações, pois os resultados esperados que afetam os indivíduos que são atendidos são a sua recuperação. Este profissional deve ser um referencial para pacientes e familiares durante os atendimentos hospitalares, já que a doença pode modificar a perspectiva e a capacidade de enfrentar as dificuldades por parte do doente e seus familiares.

Nos estágios tivemos a oportunidade de presenciar o direcionamento dos programas quanto aos serviços de saúde, com relação ao acesso a informação e o acolhimento executado em um hospital público, nessa experiência observaram-se, então, a dificuldade no repasse de tais informações.

\section{EMBASAMENTOS TEÓRICOS}

No ambiente hospitalar Ferreira (1975, p 27), diz que 'acolher é dar acolhida, admitir, aceitar, dar ouvidos, dar crédito, agasalho, receber e atender'. A inserção do Serviço Social no campo da saúde de acordo com Bravo (2007, p.43) deve ocorrer com 'o intuito de formular estratégias que busquem reforçar ou criar experiências nos serviços de saúde, articulando as suas ações ao Projeto da Reforma Sanitária'.

Observamos que as dificuldades encontradas no acolhimento são quanto a apreensão de seus conceitos por parte dos trabalhadores em saúde. As equipes de saúde I79requentemente deparam-se com questões como: Quem acolhe? Qual é o horário do 
acolhimento? Em qual lugar? Tais perguntas mostram, muitas vezes, a dificuldade, por parte dos trabalhadores, do que vem a ser o acolhimento. $O$ mesmo não pressupõe hora, local ou profissional específico para fazê-lo, devendo a "postura acolhedora" fazer parte das habilidades dos membros das equipes em sua relação com a população, em todos os momentos, facilitando o acesso as informações necessárias. Sendo o conceito de acolher:

5. Dar ou receber abrigo, proteção, agasalho; ABRIGAR (-SE) [td. : acolher crianças abandonadas.] [toda. : Por causa do mau tempo, acolheu -nos em sua casa.] [ta. : Os flagelados acolheram-se na escola] 2. Dar ou ter acolhida, hospitalidade; dar ou ter alojamento; HOSPEDAR (-SE); RECOLHER (-SE) [td.: Acolheu os primos vindos da Austrália.] (CALDAS, 2014).

No dia-a-dia de um hospital público, as equipes devem se preparar para utilizar a sua infra-estrutura de forma criativa, garantindo os pressupostos do acolhimento, adequado às realidades locais. Reconhecer e acolher o desejo do outro não implica na sua satisfação.

A ação resolutiva não se reduz a uma conduta, como aborda Merhy (1994, p. 139), esta afirma que, resolutividade: 'é colocar à disposição do paciente (usuário, cliente) toda a tecnologia disponível a fim de se conseguir o diagnóstico e o tratamento adequado a cada caso'.

Dessa forma, as decisões do usuário podem não coincidir com as do profissional, assim Goldim (2002) alerta que quanto melhor o vínculo entre o usuário e o profissional, maior o conhecimento e menores as possibilidades de conflitos de interesse, resultante da Anamnese que se refere especialmente à relação médicopaciente, devido a'A anamnese (do grego anamnesis significa recordação) consiste na história clínica do paciente, ou seja, é o conjunto de informações obtidas pelo médico por meio de entrevista previamente esquematizada.' (UNIFESP, 2014).

A partir destas informações, podemos entender 'acolher' como o tratamento de recepção a uma pessoa, desde o 'Bom Dia!' ao oferecimento de um assento, um copo de água, etc. A 'anamnese' já é entendida como um procedimento da área médica que 
consiste na entrevista direcionada ao paciente, buscando em sua história de vida os antecedentes que justifiquem seu estado de saúde atual. (UNIFESP, 2014).

Além disso, se faz necessário oferecer condições aos usuários para que sejam protagonistas de sua própria história, o chamado empoderamento que segundo Schiavo e Moreira (2005).

Implica, essencialmente, a obtenção de informações adequadas, um processo de reflexão e tomada de consciência quanto a sua condição atual, uma clara formulação das mudanças desejadas e da condição a ser construída. A estas variáveis, deve-se somar-se uma mudança de atitude que impulsione a pessoa, grupo ou instituição para a ação prática, metodológica e sistemática, no sentido dos objetos e metas traçadas, abandonando-se a antiga postura meramente reativa ou receptiva.

De acordo com Soares (2000), quando os usuários se recusam a receber determinado cuidado e tentam exercer sua cidadania, reivindicando o exercício de seus direitos, geralmente os profissionais da saúde lançam mão de mecanismos disciplinares, desencadeando um processo de recriminações e de não apoio a eles. Os usuários passam a ser rotulado de 'cliente chato', 'cliente rebelde'.

Na concepção de Ramos e Lima (2003, p, 124), 'o acolhimento deve propiciar um ambiente de relação empática, capaz de identificar e resolver ou direcionar ao ponto de resolução as necessidades do cliente, buscando dar suporte às demandas populacionais que chegam aos serviços'.

Ainda segundo Fracolli, (200I, p. 9-13) 'o acolhimento é um instrumento de trabalho que incorpora as relações humanas. É um instrumento, pois deve ser apropriado por todos os trabalhadores de saúde em todos os setores do atendimento'. Assim, não se limita ao ato de receber, mas a uma sequência de atos e modos que compõem o processo de trabalho em saúde.

Dessa forma, 'acolher' não significa a resolução completa dos problemas referidos pelo usuário, mas a atenção dispensada na relação, envolvendo a escuta, a valorização de suas queixas, a identificação de necessidades, sejam estas do âmbito individual ou coletivo, e a sua transformação em objeto das ações de saúde.

Segundo Merhy (1994, p. 139) os direitos ao acesso a todo tipo de recurso e de ser encaminhado a serviços que disponham de assistência fazem parte do princípio de 9 resolutividade. Este direito foi citado por Merhy (1994) expondo a necessidade de se 
oferecer toda a tecnologia necessária para a resolução dos problemas do usuário e o encaminhamento a todo e qualquer serviço, na área da saúde, que se fizer necessário.

É importante ressaltar, que a informação visa à educação, ou seja, uma mudança de comportamento, a aquisição de autonomia do usuário, e não simplesmente a orientação informativa. A orientação tem a função de formar cidadãos e não analfabetos informados e entendidos. (BORDENAVE, 1994).

Se tratando da prática profissional, Nobre, 2009 (apud BABTISTA, 2009, p. 17). Afirma que as relações que a configuram são complexas. Em primeiro lugar, elas expressam determinado tipo de intervenção no âmbito das práticas sociais, nesse sentido a prática profissional, segundo a autora, situa-se no '[...] âmbito das relações sociais concretas de cada sociedade, abrigando em sua configuração as sínteses do seu movimento histórico'.

Para Nobre, 2009 (apud BABTISTA, 2009 p. 13), a prática social vista como categoria teórica '[...] possibilita o conhecimento e a explicitação do processo pelo qual se constitui e se expressa o ser social, e da dinâmica da construção histórica do mundo humano-social'. Desse modo, pode-se entender que a divisão das ideias ou definições teóricas que compõem a prática social define a concepção do ser social e de toda a dinâmica que envolve a sua vivência.

Sobre a complexidade das relações profissionais e Cotidianas, o Conselho Federal de Serviço Social, em cartilha intitulada 'Os parâmetros para Atuação do Assistente Social na Política de Assistência Social' ressalta:

O Serviço Social como profissão, em sete décadas de existência no Brasil e no mundo, ampliou e vem ampliando o seu raio ocupacional para todos os espaços e recantos onde a questão social explode com repercussões no campo dos direitos, no universo da família, do trabalho e do 'não trabalho', da saúde, da educação, dos (as) idosos (as), da criança e dos (as) adolescentes, de grupos étnicos que enfrentam a investida avassaladora do preconceito, da expropriação da terra, das questões ambientais resultantes da socialização do ônus do setor produtivo, da discriminação de gênero, raça, etnia, entre outras formas de violação dos direitos. Tais situações demandam ao Serviço Social projetos e ações sistemáticas de pesquisa e de intervenção de conteúdos os mais diversos, que vão além de medidas ou projetos de Assistência Social. 


\section{METODOLOGIA:}

Utilizamos como metodologia para este trabalho a Pesquisa Explicativa Descritiva. Segundo GIL, (2011. P 28) 'Pesquisas explicativas são aquelas pesquisas que tem como preocupação central identificar os fatores que determinam ou que contribuem para a ocorrência dos fenômenos'. Iremos utilizar o método dialético que consiste na arte do diálogo.

Segundo Gil (2008, p I4), a 'dialética fornece as bases para uma interpretação dinâmica e totalizante da realidade, já que estabelece que os fatos sociais não podem ser entendidos quando considerados isoladamente, abstraídos de suas influências políticas, econômicas e culturais'.

Percorremos as dependências de um hospital público para a realização da coleta de dados pra darmos resposta ao projeto de pesquisa. O mesmo está localizado na Rua Bahia, Bairro Caminho das Árvores.

Para a coleta de dados foram realizadas pesquisas documentais, com o objetivo de darmos reposta de como ocorre o acolhimento em um hospital público. Houve a realização de mapeamento da rede de saúde pública, sobre os programas e serviços da atenção primária; realizada com equipe da direção do hospital, em número de 02 profissionais, que responderam quais as demandas dos programas e como se dar o acesso a estes serviços, quais são suas potencialidades e fragilidades, etc.

Realizamos a técnica de grupo focal, com usuários dos serviços do hospital público que estavam aguardando consultas médicas, convidamos para a pesquisa o total de o8 (oito) usuários por amostragem, ao explicarmos qual era o objetivo da entrevista, repassamos os termos de consentimento livre e esclarecido.

A utilização deste instrumental deu subsídio para a pesquisa sobre os serviços prestados no hospital público, e por sua vez, nos proporcionou desvendar as problemáticas que são vivenciadas nestes serviços e as práticas já estabelecidas e obter sugestões de melhoria quanto aos programas existentes no hospital.

\section{RESULTADOS E DISCUSSÃO}

Apresentaremos análises qualitativas da coleta de dados realizada durante a pesquisa. Usaremos também para a análise a técnica SWOT que é uma ferramenta 
utilizada para fazer análise de ambientes, é empregada em processos de planejamento estratégico, avaliação da situação da organização e de sua capacidade de competição no mercado. No decorrer do processo de coleta de dados, a mesma foi subdividida em três etapas, cuja primeira foi com propósito de analisar como ocorre o acolhimento dos serviços e programas, a segunda sobre o mapeamento dos mesmos, a terceira como se dá os serviços na visão dos usuários em um hospital público.

5.I Análise de pesquisa documental sobre como é executado o acolhimento social em um hospital público.

Quadro or: Demonstrativo do resultado da pesquisa documental validada com documentos que comprovem a existência.

\begin{tabular}{|l|l|}
\hline \multicolumn{1}{|c|}{ Dados de Levantamento } & $\begin{array}{c}\text { Resultado da pesquisa Documental. } \\
\text { Validada com documentos que } \\
\text { comprovem a existência. }\end{array}$ \\
\hline & \\
\hline $\begin{array}{l}\text { Cxiste Plano Operacional Padrão (POP) } \\
\text { de acolhimento do Serviço Social. }\end{array}$ & \\
\hline $\begin{array}{l}\text { Como é o fluxo de esclarecimento dos } \\
\text { direitos à saúde dos usuários }\end{array}$ & \\
\hline $\begin{array}{l}\text { O registro do acolhimento nos } \\
\text { prontuários pelo profissional de Serviço } \\
\text { Social. (pesquisa in lócus no prontuário) }\end{array}$ & $\begin{array}{l}\text { É feito somente para pacientes } \\
\text { internados. }\end{array}$ \\
\hline $\begin{array}{l}\text { Quais Informativos existentes sobre os } \\
\text { direitos à saúde, como: TFD; Pacientes } \\
\text { de câncer, com transtornos mentais e } \\
\text { síndromes em relação ao acompanhante } \\
\text { ou responsável. }\end{array}$ & $\begin{array}{l}\text { Ónico informativo } \\
\text { encontrado foi sobre o programa TFD. }\end{array}$ \\
\hline
\end{tabular}


Como é o acolhimento na admissão do paciente na internação. Existe fluxograma?

Após o acolhimento como se dá os fluxos de acessos aos programas da atenção primária. Como é realizado os acompanhamentos pelo Serviço Social.

Como é o fluxograma da Rede de Atenção Primária do SUS.

Fonte: pesquisa documental em Hospital Público -2014.

5.2 Mapeamento da rede de saúde pública, sobre os programas e serviços da atenção primária através de tabela;

Tabela or - Mapeamento dos Programas em um Hospital Público sobre o acolhimento

\begin{tabular}{|c|c|c|c|c|c|}
\hline Programas & Acesso & Técnica & $\begin{array}{c}\text { Público } \\
\text { Alvo }\end{array}$ & $\begin{array}{c}\text { Potencialidad } \\
\text { e }\end{array}$ & $\begin{array}{c}\text { Fragilidade } \\
\mathbf{s}\end{array}$ \\
\hline $\begin{array}{l}\text { Planejament } \\
\text { o familiar }\end{array}$ & $\begin{array}{l}\text { Não tem } \\
\text { demanda }\end{array}$ & $\begin{array}{l}\text { Seria } \\
\text { atendiment } \\
\text { o individual }\end{array}$ & $\begin{array}{l}\text { Mulheres } \\
\text {, homens } \\
\text { e casais } \\
\text { em idade } \\
\text { fértil }\end{array}$ & $\begin{array}{l}\text { Contraceptivo } \\
s \text { adequados }\end{array}$ & $\begin{array}{l}\text { Ausência } \\
\text { de } \\
\text { informação }\end{array}$ \\
\hline Pré-natal & $\begin{array}{l}\text { Encaminha } \\
\text {-mento } \\
\text { médico e } \\
\text { demanda } \\
\text { espontânea } \\
\text {. }\end{array}$ & $\begin{array}{l}\text { Teste } \\
\text { rápido, } \\
\text { palestras, } \\
\text { vacinas, } \\
\text { exames e } \\
\text { encaminha- } \\
\text { mentos } \\
\text { para a rede } \\
\text { multiprofis } \\
\text {-sional. }\end{array}$ & $\begin{array}{l}\text { Gestante } \\
\mathrm{s}\end{array}$ & $\begin{array}{l}\text { Execução } \\
\text { adequada de } \\
\text { tudo que é } \\
\text { proposto na } \\
\text { técnica de } \\
\text { atendimento. }\end{array}$ & $\begin{array}{l}\text { Precocidad } \\
\text { e }\end{array}$ \\
\hline Tuberculose & $\begin{array}{l}\text { Não há } \\
\text { índice }\end{array}$ & - & $\begin{array}{l}\text { Pacientes } \\
\text { infecta- } \\
\text { dos }\end{array}$ & $\begin{array}{l}\text { Medicação } \\
\text { adequada }\end{array}$ & - \\
\hline
\end{tabular}




\begin{tabular}{|c|c|c|c|c|c|}
\hline $\begin{array}{l}\text { Hanseníase } \\
(\mathrm{MH})\end{array}$ & $\begin{array}{l}\text { Encaminha } \\
\text {-mento } \\
\text { médico e } \\
\text { demanda } \\
\text { espontânea } \\
\text {. }\end{array}$ & $\begin{array}{l}\text { Atendimen } \\
\text {-to } \\
\text { individual e } \\
\text { I a dose } \\
\text { assistida }\end{array}$ & $\begin{array}{l}\text { Pacientes } \\
\text { infecta- } \\
\text { dos }\end{array}$ & $\begin{array}{l}\text { Medicação } \\
\text { adequada } \\
\text { consultas } \\
\text { periódicas }\end{array}$ & $\begin{array}{l}\text { Resistência } \\
\text { ao } \\
\text { tratamento } \\
\text { por parte } \\
\text { dos } \\
\text { usuários }\end{array}$ \\
\hline Hipertensão & $\begin{array}{l}\text { Encaminha } \\
\text {-mento } \\
\text { médico e } \\
\text { demanda } \\
\text { espontânea }\end{array}$ & $\begin{array}{l}\text { Atendimen } \\
\text {-to } \\
\text { individual e } \\
\text { orientações } \\
\text { sobre a } \\
\text { medicação }\end{array}$ & $\begin{array}{l}\text { Pacientes } \\
\text { hiperten- } \\
\text { sos e } \\
\text { diabético } \\
\text { s }\end{array}$ & $\begin{array}{l}\text { Medicação } \\
\text { adequada } \\
\text { consultas } \\
\text { periódicas }\end{array}$ & $\begin{array}{l}\text { Negligênci } \\
\text { a ao } \\
\text { tratamento } \\
\text { por parte } \\
\text { do usuário }\end{array}$ \\
\hline TFD & $\begin{array}{c}\text { Pacientes } \\
\text { com laudo } \\
\text { médico }\end{array}$ & $\begin{array}{c}\text { Orientaçõe } \\
\text { s gerais }\end{array}$ & $\begin{array}{l}\text { Pacientes } \\
\text { com } \\
\text { tratamen } \\
\text {-to fora } \\
\text { do } \\
\text { municípi } \\
\text { o de } \\
\text { residênci } \\
\text { a }\end{array}$ & $\begin{array}{l}\text { Informativos } \\
\text { e instrução de } \\
\text { processos }\end{array}$ & $\begin{array}{c}\text { Ausência } \\
\text { de casas de } \\
\text { apoio }\end{array}$ \\
\hline
\end{tabular}

Fonte: Mapeamento Hospital Público (2014)

Tabela 2 - Mapeamento dos Serviços em um Hospital Público de grupos prioritários de Risco e Vulnerabilidade

\begin{tabular}{|c|c|c|c|}
\hline Público prioritário & Referência & Como funciona & Onde \\
\hline Câncer & $\begin{array}{l}\text { Hospital Ophir } \\
\text { Loyola }\end{array}$ & $\begin{array}{lr}\text { Através } & \text { de } \\
\text { agendamento } & \text { com } \\
\text { referência e contra } \\
\text { referência }\end{array}$ & Belém - PA \\
\hline $\begin{array}{l}\text { Síndrome de } \\
\text { Down }\end{array}$ & Ures-Infantil & $\begin{array}{lr}\text { Através } & \text { de } \\
\text { agendamento } & \text { com }\end{array}$ & Belém - PA \\
\hline
\end{tabular}




\begin{tabular}{l|l|l|l}
\hline & & $\begin{array}{l}\text { referência e contra } \\
\text { referência }\end{array}$ & \\
\hline HIV Positivo & URE-DIPE & Demanda espontânea & Belém - PA \\
mentais & $\begin{array}{l}\text { Hospital das } \\
\text { Clínicas } \\
\text { Gaspar Viana. }\end{array}$ & $\begin{array}{l}\text { Agendamentos com } \\
\text { referências } \\
\text { pacientes em surtos. }\end{array}$ & Belém - PA \\
\hline Hanseníase & $\begin{array}{l}\text { Marcelo } \\
\text { Cândia }\end{array}$ & $\begin{array}{l}\text { Demanda espontânea, } \\
\text { porém com referência. }\end{array}$ & Belém - PA \\
\hline Tuberculose & Barros Barreto & $\begin{array}{l}\text { Agendamentos com } \\
\text { referência e contra- } \\
\text { referência }\end{array}$ & Belém - PA \\
& &
\end{tabular}

Fonte: Mapeamento Hospital Público (2014)

Tabela 3 - Mapeamento dos Serviços em um Hospital Público

\begin{tabular}{|c|c|c|c|c|c|}
\hline $\begin{array}{c}\text { Cidades } \\
\text { pactuadas }\end{array}$ & $\begin{array}{l}\text { Serviços } \\
\text { prestados }\end{array}$ & Potencialidades & Fragilidades & Entraves & Limites \\
\hline Paragominas & $\begin{array}{c}\text { Neurologia, } \\
\text { Traumatologia, } \\
\text { Urologia, } \\
\text { Cardiologia. }\end{array}$ & - & - & - & - \\
\hline Belém & $\begin{array}{c}\text { Oncologia, } \\
\text { Doenças } \\
\text { Infectoviráis, } \\
\text { Traumatologia, } \\
\text { Urologia, }\end{array}$ & - & - & - & - \\
\hline
\end{tabular}




\begin{tabular}{c|c|c|c|c|c}
\hline & $\begin{array}{c}\text { Exames, } \\
\text { Otorrinolaringol } \\
\text { ogia }\end{array}$ & - & & & \\
\hline Marabá & - & - & - & - & - \\
\hline Castanhal & $\begin{array}{c}\text { Exames } \\
\text { (Ressonâncias) }\end{array}$ & - & - & - & - \\
\hline
\end{tabular}

Fonte: Mapeamento Hospital Público (2014)

\subsection{Avaliação com os usuários sobre o acesso aos programas e serviços ofertados no} Hospital Público através da técnica de grupo focal.

Para atingir um dos objetivos da pesquisa, que seria avaliar com os usuários sobre como ocorre o acesso aos programas e serviços ofertados no Hospital Público, no que, a coleta de dados demos inicio com técnica de grupo focal, realizamos o convite aos usuários que estavam aguardando consulta, a participarem da técnica e na obtenção de resposta acerca do problema apresentado no projeto, antes de iniciarmos os questionamentos, informamos qual era o objetivo da reunião, além da aplicação dos termos de consentimento (Brasil, 2012).

Por sua vez, demos prosseguimento com a entrevista, que deu-se no espaço do hospital municipal, com o8 usuários, sendo que esses mostraram-se com muito interesse e disposição para participarem da técnica.

A princípio ficaram receosos em dar sua contribuição, mas fomos conversando e assim sentiram-se calmos e relataram as suas necessidades, e de que forma as mesma estão sendo suprida pelos serviços prestados pela unidade de serviço de saúde publica.

Posteriormente, houve questionamento sobre a forma de recepção nas dependências do hospital público, então nos relatos dos entrevistados, salientaram que são satisfatórios com a equipe da recepção, mas o ponto crucial que mensuraram é que 'o tempo de espera pelo atendimento é longo e angustiante', ficando ansiosos, pois 
todas as etapas são longas, com relação a todos os atendimentos disponíveis no hospital público, e os serviços oferecidos pelas unidades pactuadas com a mesma, toda esta problemática deixa os usuários apreensivos, possibilitando a interferência e agravamento no quadro clínico dos mesmos.

Segundo Batista, Silva, Elias (2009), o acolhimento consiste em inverter a lógica da organização e funcionamento dos serviços de saúde, partindo dos seguintes princípios: Atender a todas as pessoas que procuram os serviços de saúde, garantindo a acessibilidade universal. Assim, o serviço de saúde assume sua função precípua, a de acolher, escutar e dar uma resposta positiva, capaz de resolver os problemas de saúde da população. Pois o processo de acolhimento dar-se na escuta do usuário, comprometendo-se a resolver seu problema de saúde. Qualificar a relação trabalhadorusuário, que deve dar-se por parâmetros humanitários, de solidariedade e cidadania.

Com a continuidade da entrevista relataram também que a forma de serem conduzidos os serviços não atende e nem supre todas as necessidades dos usuários gerando um desconforto no ambiente hospitalar, relacionados ao descontentamento dos mesmos, pois relatam ainda que precisam ser adequados os serviços dando maior atenção para os que têm urgência, confirmado com diagnóstico.

Ressaltaram ainda que, com o tempo de espera juntamente com o abalo psicológico, pode levar ao agravamento da patologia. Já com relação ao ambiente físico do hospital, segundo os relatos, estes se encontram em boas condições, havendo até melhorias no ambiente de internação com disponibilidade de centrais de ar e televisores.

Já sobre seus direitos, relataram que não são cumpridas as normas estabelecidas quanto, ao atendimento por ordem de chegada, sendo que alguns usuários são privilegiados por amizades pessoais, por partes de alguns profissionais que se deixam levar pela ausência de profissionalismo.

Também relataram a falta de atenção no momento da entrega dos agendamentos para as consultas e atendimentos, a qual se destina o determinado atendimento, gerando insatisfação. Indicaram também a carência de acesso a informação com relação aos programas e serviços prestados pela instituição. 
Segundo a Constituição Federal, das disposições gerais no Art. $2^{\circ}$ a saúde é um direito fundamental do ser humano, dever do Estado prover as condições indispensáveis ao seu pleno exercício. No § I $\mathrm{O}$ dever do Estado de garantir a saúde, e também consiste na formulação e execução de políticas econômicas e sociais que visem à redução de riscos de doenças e de outros agravos e no estabelecimento de condições que assegurem acesso universal e igualitário às ações e aos serviços para a sua promoção, proteção e recuperação.

Durante o debate houve a participação de todos os integrantes interagindo com as propostas estabelecidas na entrevista. E ainda sugeriram que deveriam ter informativos 16 em murais, para maior acesso a informação dos usuários com os serviços e programas disponíveis na instituição.

\section{CONSIDERAÇÕES FINAIS.}

Com base nos resultados da análise dos dados efetuados no corpo deste trabalho, foi possível identificar a forma de como se dá os serviços e programas em um hospital público. Neste estudo buscamos referencial teórico que nos trouxe subsídios para maior entendimento na abrangência da problemática identificada, e a forma de avaliarmos os questionamentos levantados. Foi possível confirmar a dificuldade existente no acesso a informações para a garantia de direito para com os usuários através de pesquisa documental de como é o acolhimento social em um hospital público, com base nos dados coletados confirmamos nosso levantamento de se faz necessário a implantação de novos seguimentos de trabalhos como, Plano Operacional Padrão (POP), informatizar e formular panfletos e anúncios para que os usuários tenham maior acesso a informação.

Realizamos mapeamento da rede de saúde pública sobre os programas e serviços da atenção primária e identificamos que existe um padrão de funcionamento, como a pactuação com outras instituições que atendem as demandas encaminhadas pelo 
município, mas a burocracia e o tempo de espera são os entraves que torna angustiante todo o processo até os usuários terem acesso a estes serviços.

Avaliamos com os usuários sobre o acesso aos programas e serviços ofertados em um hospital público através da técnica de Grupo Focal. Com a realização dessa coleta de dados confirmou-se através dos relatos que existem muitos entraves entre os serviços e os usuários, confirmando mais uma vez a problemática levantada em nosso artigo a respeito da deficiência de acesso a informação e o cumprimento da garantia de direitos dos usuários.

Chegamos à conclusão de que o (a) Assistente Social tem grande importância nesse processo. Este profissional deve montar estratégias para a busca de renovo incessante na garantia de direitos para com todos os usuários, devem acolher e orientar. Sendo assim, no ambiente hospitalar, a intervenção e a interação do (a) Assistente Social é primordial para a transferência de informações, pois os resultados esperados iram afetar positivamente os indivíduos.

\section{REFERÊNCIAS}

BARDIN, L. Análise de conteúdo. Ed. rev. e amp. Tradução de Luís Antero Reto e Augusto Pinheiro. São Paulo. Edições 7o, 201I, 279 p.

BRAGA, Ascensão. A Gestão da Informação. Resumo do Trabalho realizado a partir de Tese de Mestrado em Gestão - Universidade da Beira Interior (1996). Disponível em. Acesso em: o5 fevereiro 2018.

BRASIL. RESOLUÇÃO № 466, de 12 de Dezembro de 2012 do Conselho Nacional de Saúde - CNS. BRASIL. SUS. A Saúde do Brasil (Antes e Depois). Disponível em . Acesso em os de fevereiro de 2018. BRASIL. Constituição da República Federativa do Brasil. Brasília: Senado Federal, 1988.

CALDAS, Aulete. Dicionário on-line: o vocábulo acolher: Disponível em . Acesso em o6 de fevereiro de 2018. 
GATTI, Bernadete Angelina. Grupo focal na pesquisa em ciências sociais e humanas. Brasília-DF: Líber livro, 2005.

GIL, Antônio Carlos. Métodos e técnicas de pesquisa social. 5. ed. São Paulo: Atlas, 1999.

GOUREVITCH, Philip. MORRIS, Errol. Procedimento operacional padrão: uma história de guerra. São Paulo. Companhia das letras, 2008.

LAKATOS, Eva Maria. Metodologia do trabalho científico: procedimentos básicos, pesquisa bibliográfica, projeto e relatório, publicações e trabalhos científicos/Marina de Andrade Marconi, Eva Maria Lakatos - 7. Ed. - São Paulo - Atlas, 2012.

NOBRE, Elisa Cléia Pinheiro Rodrigues. Competências Profissionais. Valinhos: Anhanguera Educacional 2014, p. 26 - 28. Disponível em. Acesso em 07 de fevereiro de 2018 . 